\title{
USING MOODLE ANALYTICS FOR CONTINUOUS E-ASSESSMENT IN A FINANCIAL MATHEMATICS COURSE AT POLYTECHNIC OF PORTO
}

\author{
Ana Paula Lopes ${ }^{1}$, Filomena Soares ${ }^{2}$ \\ ${ }^{1}$ Polytechnic of Porto (P.Porto) / ISCAP - CEOS.PP (PORTUGAL) \\ ${ }^{2}$ Polytechnic of Porto (P.Porto) / ISCAP (PORTUGAL)
}

\begin{abstract}
The relevance of electronic learning, commonly called e-learning, has been growing exponentially in the last decade. Virtual learning environments (VLEs) disclosed new paths for interactions and motivation promotion, offering basic learning analytics functions and are becoming progressively popular. Moodle (acronym for Modular Object Oriented Dynamic Learning Environment) is one of the most used VLEs, it is a free learning management system distributed as Open Source. The VLE Moodle gives professors access to an "endless" use and performance database like the number of downloads for each resource, participation of students in courses, statistics of performed quizzes, among others. The data stored by Moodle offers a good and handy source for learning analytics. One popular definition, from the First International Conference on Learning Analytics and Knowledge in 2011, states that "Learning Analytics is the measurement, collection, analysis and reporting of data about students and their contexts, for purposes of understanding and optimizing learning and the environments in which it occurs". Thus, using appropriate learning analytics methods and techniques, it would be helpful to analyze what particular learning activities or tools were practically used by students in Moodle, and to what extent. Considering the importance of the student engagement and the benefits of continuous assessment in higher education, as well as the impact of information and communications technology (ICT) on educational processes, it is important to integrate technology into continuous assessment practices. Since student engagement is connected to the quality of the student experience, increasing it is one way of enhancing quality in a higher education institution.
\end{abstract}

In this study, will be demonstrated how the use of several educational resources and a low-stakes continuous weekly e-assessment in Moodle had a positive influence on student engagement in a second year undergraduate Financial Mathematics Course. Students felt that their increased engagement and improved learning was a straight result of this method. Furthermore, this suggests that wisely planned assignments and assessments can be used to increase student engagement and learning, and, as a result, contribute to improving the quality of student experience and success.

Keywords: Financial Mathematics; Assessment; Learning Analytics; Higher Education; Educational Data Mining.

\section{INTRODUCTION}

It is certain that new technologies play a fundamental and even common role in today's society. Recent developments in computation have generated many opportunities for collecting and analyzing data about learners and their contexts. The generality of online platforms, Learning Management Systems (LMS), social media, digital student records, and networked devices has led to an increase in the capture of abundant data trails that can provide insight into the learning process [1]. This development of technology-enhanced learning environments brings new opportunities for reconstructing and analyzing students' learning behavior. Therefore, Higher Education Institutions (HEI) are developing and implementing learning analytics systems to better support and understand student learning performance. Over the past few years there have been several shifts in educational settings in HEI to b-learning, e-learning, the introduction of Learning Management Systems (LMS) and Virtual Learning Environments (VLE) such as, for instance, Moodle, which is one of the e-learning platforms most commonly used worldwide, having a significant implementation in distance learning and boosted by the fact that it is distributed in an open source basis, facilitating the spread of information and knowledge accessibility to new universes of users.

Therefore, it was no surprise that big data analysis has found its place in the educational system and expected to be widely implemented in HEI [2]. Derived from data mining, the process of collecting, analyzing and reporting educational big data is mentioned to as Learning Analytics (LA). The most 
common definition of LA, from the First International Conference on Learning Analytics and Knowledge in 2011 (LAK11) [3], states that "Learning Analytics is the measurement, collection, analysis and reporting of data about students and their contexts, for purposes of understanding and optimizing learning and the environments in which it occurs". The data generated in educational contexts is frequently big, complex, and heterogeneous, making it challenging to understand. LA has emerged as a significant area of research into technology-enhanced learning.

Nowadays, it is relatively easy to capture rich data about students and their behaviors, however instructors typically have a hard time handling and interpreting such data, as they have a limited understanding of necessary data mining and processing techniques [4]. Although there are several datasets of learner information accessible for education field, there is still a need for improvement in the process of measuring, collecting, analyzing, reporting, and sharing data through HEI. With the extensive adoption of LMS we can refine the outcomes of learning analytics allowing us to look at student's outcomes more precisely. So, a student particular data can be used to tailor online course platforms and suggest specific resources to students. Personalized learning environments can help to foster students' skills in managing, monitoring, and reflecting their own learning [5]. Some LMS are able to increase learning capabilities via social and gaming tools; others have custom services developed to support adaptive mobile learning and ensure online exams integrity [6]. Furthermore, new data-mining approaches embedded into LMS extract information about the learning processes from raw data to allow instructors to improve their courses [7]. LA also enables the evaluation of students' online behavior, allowing to explore the meaning of this behaviour, and to influence the choices that support the pedagogical practices [8]. Therefore, learning personalization is worthwhile to enhance learning quality and effectiveness and became an important topic in scientific and educational literature ([9], [10], [11], [12]).

This research paper aims to investigate how the use of several educational resources and a lowstakes continuous weekly e-assessment in Moodle, by using Moodle Analytics, had a positive influence on student engagement in a second year undergraduate Financial Mathematics Course.

\section{LEARNING ANALYTICS AND VISUAL ANALYTICS}

HEI have always collected and held many data about students, but the appearance of big data analysis, online learning environments and, consequently, huge amounts of available data, have led to increased concern about gathering and analyzing students' data to support and gain insight into their learning activities ([1], [13]). However, the assessment of students' performance is always a challenging and demanding task for instructors specially in online learning environments. Educators who use online learning systems are frequently required to adapt and develop their online courses to guarantee a good performance and learning competence of their students [14]. By having access to the learning analytics on students' conclusion of lessons and quiz scores, educators should have a better sense of: students' ability to follow and understand the course contents; the topics students found difficult; students' social interactions and knowledge contributions, etc. Therefore, educators should "desire" a LMS that offers learning analytics on their online courses. A typical LA process starts with the data-gathering step. In this stage, data is collected from different learners' activities when they interact with learning elements within a VLE. The next stage is the mining of the processed data, based on different mining techniques, such as clustering, classification, association rule mining, and social network analysis. Then, the results of the mining process can be presented as a widget, which might be included into a VLE. With appropriate graphical visualizations of the analyzed data, educators will be able to understand and interpret the information represented, reflect on the impact of their teaching method on the learning behavior and performance of their students, and draw first conclusions about the effectiveness of their teaching model.

To better understand learning analytics, we can visualize a cyclic process embraced by three different steps [15] (see Fig. 1):

- Data collection and pre-processing: the first step in any LA effort is to collect data from several educational environments and systems. Represents the collection of all the learning data needed for a particular method, and its transformation to a suitable format for that method.

- Analytics and action: contains the analysis and visualization of the information taken out from step 1 as well as the actions, based on that information.

- Post-processing: based on a continuous improvement philosophy. It includes all the changes to the method explained in step 1 and 2 . It can involve compiling new data from additional data 
sources, refining the data set, determining new attributes required for a new iteration, identifying new indicators/metrics, modifying the variables of analysis, or choosing a new analytics method.

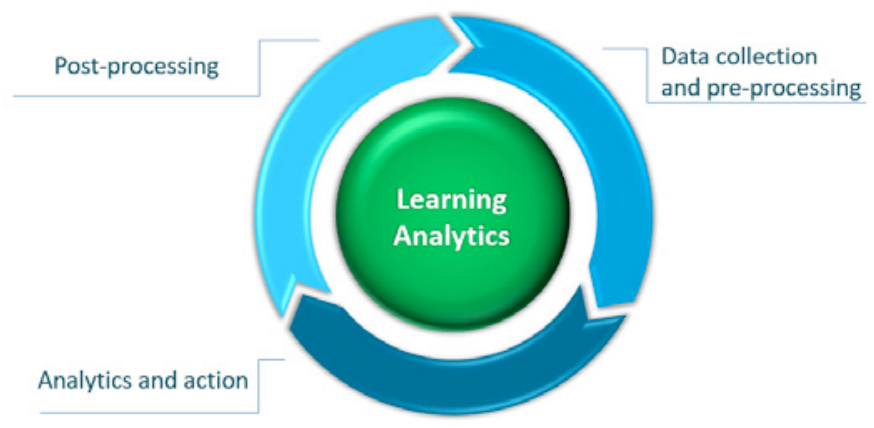

Figure 1. Learning Analytics Process (Adaptation from [15]).

The Moodle platform provides the teacher/administrator different learning analytics tools with a wide range of information reports on the numerous activities carried out by their students in a particular subject, which can be an important tool to improve and modify the subject in question. Thus, there are several reports, blocks and other plugins for Moodle, that provide learning analytics, of which we highlight and briefly describe those that we find most effective and important:

GISMO is a Visual Analytics tool for Moodle which is used to analyze the general learning process of all students in all subjects (see Fig. 2). It is incorporated with Moodle as a supplement block within the graphics environment which is visible only by the teacher/administrator. GISMO uses log data, edits them and produces graphical representations to be used by teachers to examine the social and behavioral students' interactions. It provides analytic statistical representations and shows a general "picture" of the students as a whole, analyzing a more general learning process of all the students on all subjects ([8], [16], [17]). It can also provide analytical statistic representations for specific students, resources and activities.

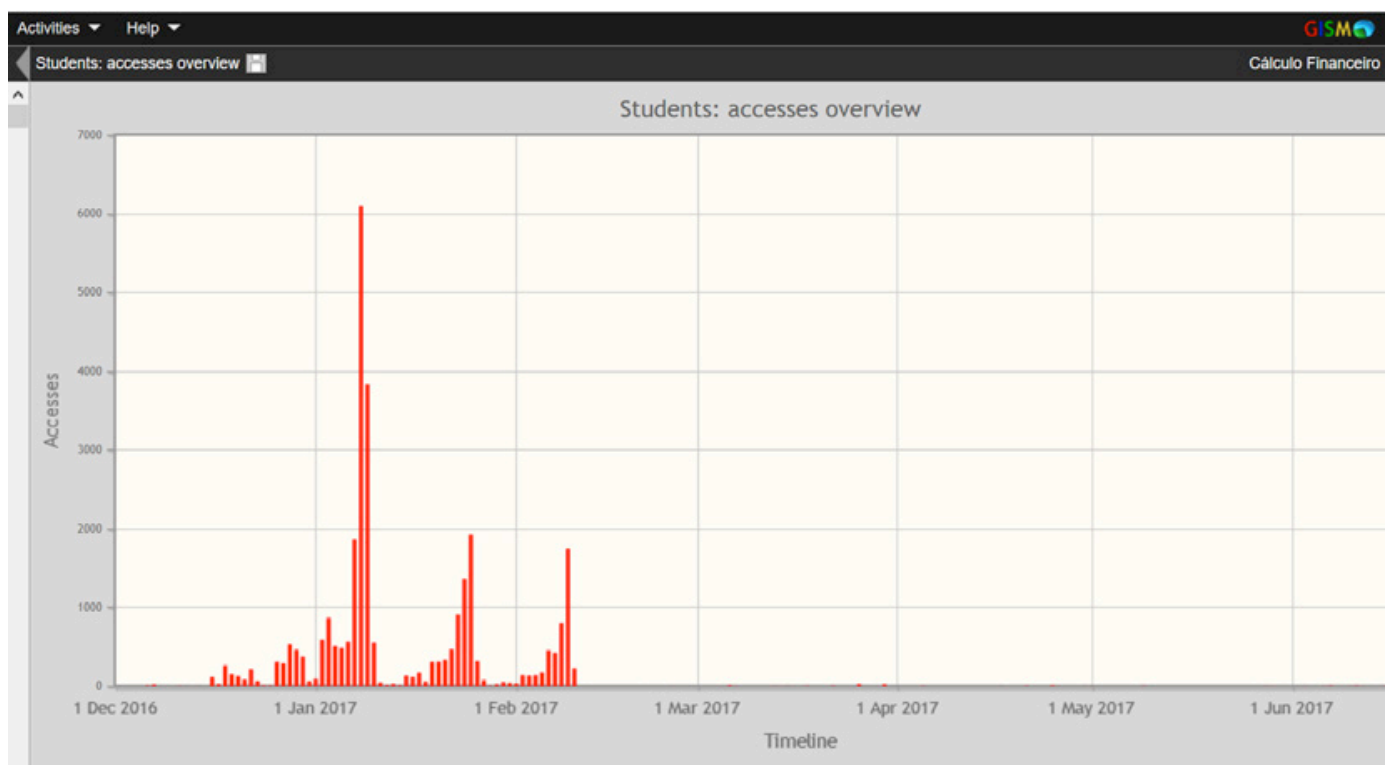

Figure 2. Number of students accesses to the Financial Mathematics Course in the Winter Semester 2017

MOCLog is a set of tools that are used for analysing and presenting data within Moodle. The development of this tool was based on GISMO. It depends on analysing interactions occurring in an online course to achieve better analysis of both the products and the educational process. The system users have access to summative reports of interactions related to actions on learning objects (resources and tools) such as quizzes and assignments. The goal is to measure the status of activities in the online-course as much as possible without distortions, 'objectively', by relying exclusively either 
on log file data or on planning data provided by the course administrators and by the teachers as reference values. The benefits of MOCLog for $\mathrm{HEI}$ are:

- Offer significant interpretation schemes for log file analysis

- Adequate interpretation schemes for transfer to other LMS

- Enables a simple and rapid analysis of the log files in the online courses in Moodle

- Feedback (numeric and graphic) for all stakeholders of the LMS (Student, Teacher, Study Program Manager, Administrator) [18].

Learning Analytics Enhanced Rubric (LAe-R) is based on the concept of assessment rubrics technique. It contains different criteria and grading levels that are associated with data extracted from the analysis of learners' interaction and learning behavior in the learning environment. It allows the instructor to customize and add different types of criteria associated to Learning and Interaction Analysis Indicators. Based on the criteria, the tool analyzes and visualizes the associated types of data [19].

Engagement Analytics is a Moodle plugin that provides information about student progress against a range of indicators. It provides feedback on the level of "engagement" of a student, where "engagement" refers to activities which have been identified by current research to have an impact on student success in an online course. It also provides the instructors with a quick graphical snapshot of which students are at risk (see Fig. 3). The purpose of this plugin is to provide teaching with information only, it does not automatically take any action based on the indicators eg NO email or notification is sent to students automatically. If desired the teacher would follow up on the information themselves, based on what they know about the student and their other communications [20].

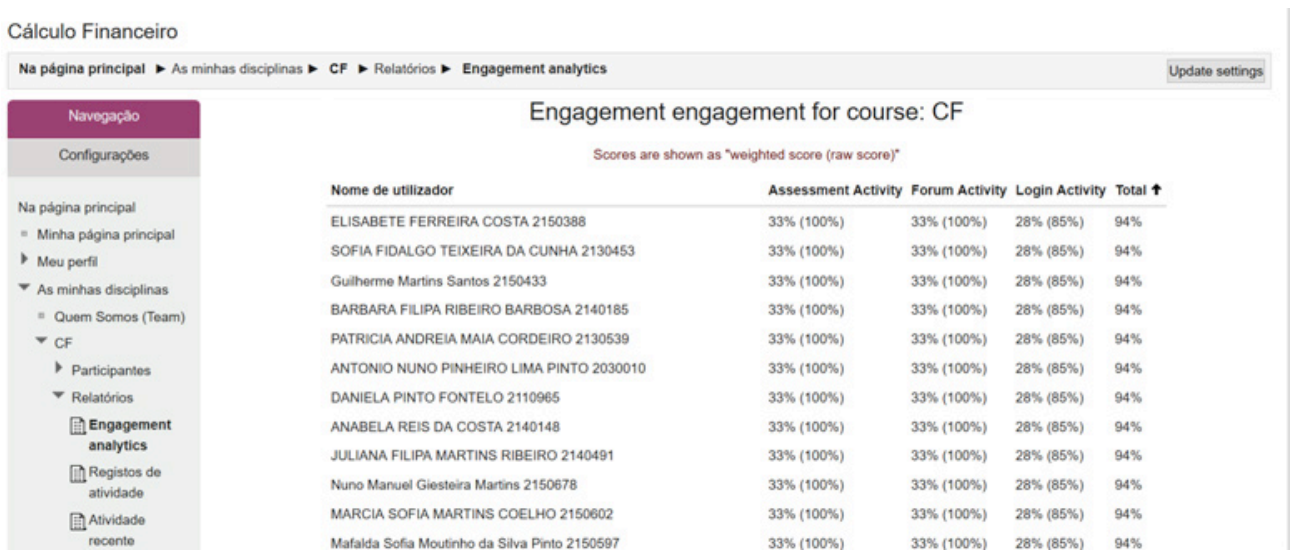

Figure 3. Engagement Analytics Report example from Financial Mathematics Course

SmartKlass is a Learning Analytics Moodle dashboard that should be included as a part of the Moodle virtual learning platform to empower teachers to manage the learning journey of their students. With this tool, Teachers can monitor students' progress from three dimensions: individual work, collaborative and results, take action and provide feedback and guidance when needed. Students can view their course overall, know their performance compared to the rest of the group and to the initially expected pace set by the teacher, and improve [21].

Mindmaps Course is one of the current Moodle activities that allow instructors and students to create concept interactive maps online, where users can enter course elements (like sections, modules, lessons and pages) directly from the map and it shows conditional activity dependencies. It provides users with a visual representation of the types, timing and weighting of assessments across a course and shows how and where the Graduate Attributes are embedded and assessed throughout the course. This visual tool helps in designing and redesigning the course itself [21].

\section{METHODOLOGY}

This study is being carried out, as a different approach to the teaching/learning process in Mathematics, at a Higher Education Institution. This was implemented in 2014-2015, 2015-2016 and 2016-2017 in an undergraduate Financial Mathematics Course (FMC) at Institute of Accounting and 
Administration of Porto (ISCAP) from Polytechnic of PORTO (P.PORTO), supported by an online Math project developed at P. Porto: MatActiva Project. The Project mission is to offer to ISCAP students a free, online tool, which stores wide variety of instructional Math resources, including video lectures and hundreds of exercises (all of them with a suggestion for the solution). It is a personalized learning platform in which students can individually and independently learn through an entire Math subject. The FMC is a second-year one in the undergraduate Accounting degree. Having some background analytics experience, granted by Moodle platforms and MatActiva Project ([22], [23], [24], [25]), we have developed a FMC that used a flipped classroom model. The sample of our study, from the Winter Semester FMC, in ISCAP, consisted of 803 students, 283 students enrolled in 2016, 262 students in 2015 and 258 students in 2014 semester. These students were divided in two groups: flipped and traditional group. In each year, the students from flipped group were the students of 2 classes from the total of 7 classes of Financial Mathematics. The flipped sample consisted of 80 students enrolled in 2016, 72 students in 2015 and 58 students in 2014 Winter semester. In both groups, approximately $90 \%$ of the students were attending the classes for the first time. The course entailed six subjects/sections (Simple Interest, Compound Interest, Ordinary Annuities, Annuity Due, Loan Amortization and Bonds) throughout the semester, and students were provided with flipped classroom model opportunities in five sections out of these six. It means that, five sections were flipped and only one section was traditionally taught during the semester. Accessing the MatActiva site www.matactiva.com, participants could access all the available sections in the FMC. In each section, students had at their disposal video lectures, reading, forms and sets of online exercises and online quizzes (all with solution), related with the topic. Each week a set of online assignments, from MatActiva Project, related with the subject they learned were given to the students to perform outside class and to "test" what students have learned. Instantaneous quiz feedback and the ability to repeat lecture segments helped them to clarify some "grey" points in their minds.

In order to increase engagement, some changes were made to the structure of the FMC for the flipped group. There was an entry-test introduced that verified if student mastered material from the previous class. It was a short task at the beginning of every class which had $25 \%$ impact on the final grade. Homework assignments were still voluntary, however, entry-test based on one from the homework assignments to motivate students to work at home.

To ensure the identification of which course elements should be a subject to consideration for modelling, the e-learning "adjusted" course combines the following categories of resources:

- Task (assignments to be solved during classes),

- Homework (assignments to be solved at home),

- Video (main course page with video lectures),

- External resource (URLs to external websites),

- SCORM package (lecture presentations).

\section{RESULTS}

Analyzing the student activities and measuring the respective learning outcomes is the heart of this learning analytics project.

There were 552648 log records and 43954 sessions made by the 803 students of the FMC, with 55 sessions per student, and 11 actions per session for each student, of the flipped group, in average. The data allowed us to detect difficult parts of the course content, also which kind of resources are most engaged by the students and therefore provide more of the same type, or improve the type of resources least engaged. It shows SCORM package, External resource and Video categories being better promoters of understanding financial mathematics concepts, and that students have more difficulty finding Homework and Task categories useful.

One of the significant measures as to the success, is the final exam results, so we have used these results to try to measure the success of the flipped classroom model. Table 1 shows the relationship of results of the 2014/15, 2015/16 and the 2016/17 in the traditional classroom group against flipped classroom group. 
Table 1. Measuring the success of Flipped Classroom against the Traditional Classroom.

\begin{tabular}{lccc} 
& $2014 / 2015$ & $2015 / 2016$ & $2016 / 2017$ \\
\hline $\begin{array}{l}\text { Flipped Classroom } \\
\text { Group - Success Rate }\end{array}$ & $71,4 \%$ & $90,5 \%$ & $91,2 \%$ \\
\hline $\begin{array}{l}\text { Traditional Classroom } \\
\text { Group - Success Rate }\end{array}$ & $49,2 \%$ & $62,3 \%$ & $62,7 \%$ \\
\hline
\end{tabular}

Source: Own elaboration

We can observe, from Table 1, that the success rate for the flipped classroom version increased by $19,8 \%$ from the starting point set in 2014/15. We can also notice that the success rate for the flipped classroom group is bigger than the success rate for the traditional classroom group in FMC. All iterations of flipped classroom clearly outperform the average success rate across of traditional classroom, the average success rate for the traditional classroom improved by $13,1 \%$ in $2015 / 16$ and $0,4 \%$ in $2016 / 17$, while the average success rate for the flipped classroom improved by $19,1 \%$ in $2015 / 16$ and $0,7 \%$ in $2016 / 17$. From this we can see that there was a slight increase in overall performance in the flipped classroom version in relation to successful students.

\section{CONCLUSION}

There is no doubt that new technologies play a fundamental role in today's society. Therefore, this reality demands changes in the teaching-learning process. Moodle is one of the most widely used elearning platforms (LMS) in the world. Being one of the most complete and user-friendly systems, having a significant implementation in distance learning and aided by the fact that it is distributed in Open Source, it facilitates the dissemination of knowledge and accessibility to new universes of users.

The MatActiva Project uses this platform to communicate and transmit information and knowledge, where students have access to various support materials, both to assist in the development of mathematical skills and to study the subjects taught in the FMC. We sought a way to leverage data from the platform to improve students' performance and results, since Learning Analytics allows us to have unprecedented insights into the teaching and learning process. Provided with greater knowledge, instructors can better define and measure learning goals and assess the success of FMC. They can also quickly identify where students have more difficulties and interfere to support them. In addition, Learning Analytics enables students to evaluate online behavior and explore the meaning of this behavior to influence the options that support their pedagogical practices.

To guarantee the successful completion of training and get the most accurate picture of student's progress, attitude and problems, to anticipate intentions, we need as much data as possible. Nowadays learning is supported by more than one e-learning system attending to different aspects of education. All these data need to be joined into one application in order to have more efficient LA. As we have seen in the above review, excellent free tools have been developed and continue to be updated for different types of analytics Therefore, one of the main challenges is how to merge data from several sources and numerous structures and to present them in real-time. With all of these gathered data, another challenge is to extract valuable and significative results from them in order to get the full final analysis and visualize it appropriately.

\section{REFERENCES}

[1] Siemens, G., \& Long, P. (2011). Penetrating the fog: Analytics in learning and education. Educause Review, 46(5), 30.

[2] Johnson, L., Adams, S., Cummins, M., Estrada, V., Freeman, A., \& Ludgate, H. (2013). The NMC Horizon Report: 2013 Higher Education Edition. Austin, TX: The New Media Consortium. Retrieved September 16, 2018, from http://www.nmc.org/pdf/2013-horizon-report-HE.pdf

[3] SoLAR - Society for Learning Analytics Research. 1st International Conference on Learning Analytics And Knowledge. Retrieved June 2, 2018, from https://solaresearch.org/about/ 
[4] Qu, H., \& Chen, Q. (2015). Visual analytics for MOOC data. IEEE computer graphics and applications, 35(6), 69-75.

[5] McLoughlin, C., \& Lee, M. J. W. (2010). Personalized and self regulated learning in the Web 2.0 era: International exemplars of innovative pedagogy using social software. Australasian Journal of Educational Technology, 26(1), 28e43.

[6] Fenu, G., Marras, M., Boratto, L. (2017), A multi-biometric system for continuous student authentication in e-learning platforms. In: Pattern Recognition Letters, Elsevier. doi: https://doi.org/10.1016/j.patrec.2017.03.027

[7] Conde, M. Á., Hernández-García, Á., Oliveira, A. (2015), Endless horizons: addressing current concerns about learning analytics. In: Proceedings of International Conference on Technological Ecosystems for Enhancing Multiculturality, 259- 262, ACM.

[8] Lopes, A. P., Soares, F., (2016). "The Development and Implementation of Math Projects in a Hei - Expectations, Objectives, Experiences and Analysis". In 10th International Technology, Education and Development Conference - INTED2016 Proceedings, $7^{\text {th }}-9^{\text {th }}$ March 2016, Valencia, Spain, Pages: 6522-6530, ISBN: 978-84-608-5617-7, ISSN: 2340-1079, doi: 10.21125/inted.2016.0540.

[9] F.A. Dorça, R.D. Araujo, V.C. de Carvalho, D.T. Resende, and R.G. Catellan, "An Automatic and Dynamic Approach for Personalized Recommendation of Learning Objects Considering Students Learning Styles: An Experimental Analysis," Informatics in Education, vol. 15, no. 1, pp. 45-62, 2016.

[10] E. Kurilovas, and V. Dagiene, "Computational Thinking Skills and Adaptation Quality of Virtual Learning Environments for Learning Informatics," International Journal of Engineering Education, vol. 32, no. 4, pp. 1596-1603, 2016.

[11] T. Jevsikova, A. Berniukevičius, and E. Kurilovas, E. "Application of Resource Description Framework to Personalise Learning: Systematic Review and Methodology," Informatics in Education, vol. 16, no. 1, pp. 61-82, 2017.

[12] T.M. Takala, L. Malmi, R. Pugliese, and T. Takala, "Empowering Students to Create Better Virtual Reality Applications: A Longitudinal Study of a VR Capstone Course," Informatics in Education, vol. 15, no. 2, pp. 287-317, 2016.

[13] Ferguson, R. (2012). Learning analytics: Drivers, developments and challenges. International Journal of Technology Enhanced Learning, 4(5/6), 304-317.

[14] Gasevic, D., Jovanovic, J., \& Devedzic, V. (2007). Ontology-based annotation of learning object content. Interactive Learning Environments, 15(1), 1-26.

[15] Chatti, M.A., Dyckhoff, A.L., Schroeder, U. and Thüs, H. (2012) "A reference model for learning analytics', Int. J. Technology Enhanced Learning, Vol. 4, Nos. 5/6, pp.318-331.

[16] B. Dietz-Uhler and J. E. Hurn, "Using learning analytics to predict (and improve) student success: A faculty perspective," J. Interact. Online Learn., vol. 12, no. 1, pp. 17-26, 2013.

[17] Mazza R., and Botturi L. (2007). Monitoring an online course with the GISMO tool: A case study. Journal of Interactive Learning Research, vol. 18(2), pp.251 - 265, 2007.

[18] Riccardo Mazza, Marco Bettoni, Marco Faré, Luca Mazzola. MOCLog - Monitoring Online Courses with log data. In: In Retalis, S., and Dougiamas, M. (2012). 1st Moodle Research Conference Proceedings, Heraklion, Greece, Sept. 14-15, 2012. ISBN: 978-960-98516-2-6.

[19] O. Petropoulou, K. Kasimatis, I. Dimopoulos, and S. Retalis, "LAe-R: A new learning analytics tool in Moodle for assessing students performance," Bull. IEEE Tech. Comm. Learn. Technol., vol. 16, no.1, pp. 1-13, 2014.

[20] Dawson, P., \& Apperley, T. (2012). Workshop 1: Open-Source Learning Analytics and "what the student does". Paper presented at the SoLAR Southern Flare Conference.

[21] "Moodle plugins directory." [Online]. Available: https://moodle.org/plugins/. [Accessed: 20-Nov2018]. 
[22] Torres, C., Lopes, A.P., Babo, L., Azevedo, J., (2017). MatActiva Project - A mathematical dynamic environment to engage students in the learning process. The e-Learning Excellence Awards 2017: An Anthology of Case Histories. Pages:125-138, ISBN: 978-1-911218-58-6. Academic Conferences and Publishing International Limited.

[23] Lopes, A. P., Babo, L. and Torres, C. (2015). The Impact of an Online Mathematics Education Project (MatActiva) on Higher Education Students. Proceedings of 9th International Technology, Education and Development Conference - INTED2015, March 2015, Madrid, Spain, Pages: 2921-2927, ISBN: 978-84-606-5763-7, ISSN: 2340-1079

[24] Lopes, A. P. (2011). Teaching with Moodle in Higher Education, in proceedings of INTED2011 International Technology, Education and Development Conference. Pages: 970-976, ISBN: 978-84-614-7423-3, ISSN: 2340-1079. Valencia, Spain.

[25] Babo, L., Azevedo, J., Torres, C., Lopes, A. (2010). Moodle and multiple-choice tests, in proceedings of INTED2010 - International Technology, Education and Development Conference, Pages: 296-303, ISBN: 978-84-613-5538-9, ISSN: 2340-1079, Valencia, Spain. 